\title{
Uniportal video-assisted thoracic surgery: twentieth anniversary
}

\author{
Marcello Migliore \\ Thoracic Surgery, Policlinico University Hospital, University of Catania, Catania, Italy \\ Correspondence to: Marcello Migliore, MD, PhD, FETCS. Thoracic Surgery, Policlinico University Hospital, University of Catania, Via S. Sofia 78, \\ 95124 Catania, Italy. Email: mmiglior@unict.it. \\ Comment on: Rocco G. Fact checking in the history of uniportal video-assisted thoracoscopic surgery. J Thorac Dis 2016;8:1849-50.
}

Submitted Sep 11, 2018. Accepted for publication Dec 06, 2018.

doi: $10.21037 /$ jtd.2018.12.49

View this article at: http://dx.doi.org/10.21037/jtd.2018.12.49

After 2 years, while reading the editorial entitled "Fact checking in the history of uniportal video-assisted thoracoscopic surgery" (1), an attempt to undermine the work done with tremendous sacrifice by myself and team has been noted; and therefore, as silence implies consent, but also it could be exchanged as arrogance and superiority, the reply to the editorial, step by step using particular attention to find details in the body of scientific evidence, is mandatory.

In the editorial, one can read "authors who consider themselves to be pioneers of uniportal VATS for having reported, over a 17-year period [1998-2015], rougbly 12 uniportal VATS procedures per year largely performed for pleural effusions or mediastinal conditions. In fact, no experience with uniportal VATS lung resection had been reported from this group in the two initial reports published in prestigious journals" (1).

Although it seems unclear why the editor spent time to investigate, and to report about my personal surgical performance, it is evident the attempt to minimize our experience. In fact, an unexpected wrong calculation has been made; instead of 12 patients per year, we operated 18 patients per year, and I explain the why.

In the paper, from where the writer made the wrong calculation (2), we wrote, "Since October 1998 to fune 30 2015 excluding November 1999 to Fune 2000, Fune 2004 to December 2006 and Fanuary 2009 to May 2010 (MM worked abroad) more than 300 patients have been operated using uniportal VATS technique in our thoracic unit... Two hundred fourteen patients have been operated...".

Well, periods spent abroad have not been included, and the sum of the months I spent without operating in Italy is 58 months, almost 5 years. The calculation made is therefore wrong as 214 patients should have been divided to 12 years (not 17). The result is 18 patient per year (17.8 patients) and not 12 (the result of the original division $214 / 17$ is 12.58 but it has been rounded up to 12 instead to 13 ). Thirteen or 18 operations per year, does it make a difference when a new technique is introduced? No new technique has been "big" at the beginning.

Moreover, we wrote in the paper (2) which underwent intense editorial scrutiny "In this mini-review, we excluded all patients operated with 4, 6 or $8 \mathrm{~cm}$ incision, and therefore only operations performed through a 'true' $2 \mathrm{~cm}$ incision have been included" (2).

We therefore excluded all operations for lung biopsy or other procedures which have been performed through a 4-8 $\mathrm{cm}$ single skin incision because we defined them, already in 2000, as a mini-thoracotomy (3).

Since 20 years we also performed some lung biopsies with the video-assisted thoracic surgery (VATS) technique, but we never claimed that we were the first to perform a lung biopsy through a mini-thoracotomy VATS assisted (today many surgeons call an incision of 4-6 cm as uniportal) as we operate for our patients, and not for the glory. Evermore, in the first paper (4) we explained in a table all the indications for uniportal VATS which were not only pleural effusion or mediastinal diseases as stated by the editor (1).

Nevertheless, I agree on one thing that major lung resection have not been reported. Well, I am not sure if in 1998-2000 there was a surgeon capable to perform a lobectomy through a "true" 2 -cm uniportal VATS with the surgical instrumentations available at that time, and this is the only reason why major lung resections were not published in our initial papers (4-7).

Continuing reading the editorial "In the recent literature, 
numerous attempts at performing diagnostic or therapeutic video-assisted thoracic surgery (VATS) procedures through a single port (uniportal VATS) bave been reported" $(8,9)$ and "bowever, if the literature is searched for previous manuscripts on single port thoracoscopic surgery utilized for non-pulmonary conditions, several authors have published before these valuable contributions", finally "Truth be told, the concept of uniportal VATS was proposed by Singer back in 1924 who devised an instrument to perform procedures through the same incision" (10).

At least for two reasons the evidence reported for previous uniportal VATS experiences is neither as reliable nor as ironclad as the author wants to depict it.

Firstly, regarding the concept of uniportal VATS proposed by Singer in 1924 (1). After having read the review cited in the editorial who describe the work of Singer (10), and being curious about the true history (11), I found the PDF of the original paper of Singer (12), physician in San Louis. Reading his words "I, therefore, designed an instrument patterned somewhat on Facobaeus's thoracoscope. I bave an attachment for the side opening through which various bronchoscopic instruments can be introduced under direct vision for removal of sections, and also one through which one can drain fluids and replace these with air. There is a small light in the tip of the instruments", it is evident that the extraordinary Dr. Singer experience, which it is important to remember was done with Dr. Graham, surgeon in San Louis, was a great step forward in medicine and surgery; but the fact that "the small light was in the tip of instruments" affirms that the technique used could not be defined as uniportal VATS where the optic and surgical instruments are separated to permit better maneuverability (13-15). Instead Singer and Graham work was fundamental to manufacture the wellknown classic thoracoscope where the operative channel, suction and optic are assembled together.

Secondly, reading with attention the papers of Nesher and Lin $(8,9)$, and looking the figure in the manuscripts it results evident that both Authors performed the operations using the classic thoracoscope even the word "uniportal" is written in the title of both papers: the lesson learned is that the word uniportal written in the title does not mean that the "uniportal" technique has been used.

Evermore the reader can read in the editorial "Unlike today, not many surgeons were ready to jump on the bandwagon for the fear to be run over by it. This is the real history of uniportal VATS, a technique as old as thoracic surgery itself; any other interpretation requires checking the facts. Like for all surgical techniques, it doesn't actually matter today who devised uniportal VATS_what really matters today is for the technique to stand the test of time". "In my view, a new technique is the perennial contribution a surgeon offers to the community: the very first time it is published, it doesn't belong to you anymore and... And Hence, albeit recognizing previous work in the field of uniportal VATS, this paper was focused on the description of an innovative approach to lung resection by VATS and is still considered seminal in the literature of uniportal VATS because it bas represented the first attempt at codifying a set of procedures aimed at resecting the lung through a single port technique based on an innovative geometrical approach to a target lesion in the chest."

Unfortunately, the reported "real history" of uniportal VATS is not real at all. Instead, the writer craves that it doesn't actually matter today who devised uniportal VATS but "my" paper has represented the first attempt at codifying a set of procedures aimed at resecting the lung through a single port technique based on an innovative geometrical approach to a target lesion in the chest.

This is the right moment to emphasize that although both Italians, it is evident that we are talking different languages. While on one side there is the report of "the first attempt at codifying a set of procedures aimed at resecting the lung through a single port using a geometrical approach", on the contrary I believe that as surgery is an art, the surgeon should work freely inside the chest, even through a single port, according with the intraoperative necessities, and not between the limit given by geometry.

\section{Comments}

Although the editor is in a position to check our results by analyzing the data from our paper, he did not identify a single error, but unfounded insinuations of weakness rather than judging our research on its merits could be seen reading the editorial.

For this reason, few historically information could be useful for the readers. After oral and poster presentation in regional and national meetings, the technique was presented at the American Society of Endoscopic Surgeons (SAGES) in Atlanta USA, (29 March-1 April 2000), at the Thoracic Surgery and Interdisciplinary Symposium on the Threshold of the Third Millennium, in Naples, (May 11-13, 2000), and at the European Society of Thoracic Surgeons (ESTS), in London, UK (1-3 November 2000). In the last 5 years many surgeons principally from Europe, China and Japan adopted the concept of uniportal VATS for many thoracic pathologies (16-25).

Even if many surgeons reported the true fact (26-31), 
the resulting confusion from the editorial (1) has certainly misled many readers and diverted attention from the facts of our study, and more important pose historical doubts. Although it is impossible to go inside the complexity of the brain of who wrote the editorial, sometimes people decide unconsciousness to be "denialist" because at some level it upsets them to think that the "unwanted" facts are true (32-34), and unfortunately minimization and skepticism are parts of the denialism. Moreover, it is important not to confuse denialism for genuine debate, but the wrong calculations which have been made with the aim to analyze my personal surgical performance demonstrate the evident effort to undermine a colleague and his team instead to emphasize the truth. Instead to protect science and history; the written attack should be seen for what it is-an attempt to discredit work (4-7) that has been done before his work.

Moreover, I would like to say that anyone who reads the full version of our papers (4-7) will see that we provided already in 2000-2003 detailed evidence that refutes the editorial calculations (1) that our studies could be inconsistent because of few cases operated, and because others published before.

One important question arises. What the editorial (1) is teaching me? I hope I am wrong, but it seems that the only problem for many colleagues is that the concept of single port VATS was initiated in Catania, Italy, which is not included between the known international thoracic surgery departments, and therefore it becomes "easy" to censure the work done by prejudice.

In conclusion, while the human willingness to defend personal position is understandable, claiming that science and honesty are on one's side, and the venture to pin down any experience and new ideas because of their anteriority respect to the personal own can only harm science sooner or later. There exists the human temptation that one should become a denialist too to let the original work survive, but the strongest hope is that the writer of the negative scrutiny of our papers changes his point of view, stop influencing worldwide colleagues, and permit surgical science to flow liberally.

\section{Acknowledgements}

None.

\section{Footnote}

Conflicts of Interest: The author has no conflicts of interest to declare.

\section{References}

1. Rocco G. Fact checking in the history of uniportal video-assisted thoracoscopic surgery. J Thorac Dis 2016;8:1849-50.

2. Migliore M, Calvo D, Criscione A, et al. Uniportal video assisted thoracic surgery: summary of experience, minireview and perspectives. J Thorac Dis 2015;7:E378-80.

3. Migliore M, Deodato G. Thoracoscopic surgery, videothoracoscopic surgery, or VATS: a confusion in definition. Ann Thorac Surg 2000;69:1990-1.

4. Migliore M, Giuliano R, Deodato G. Video assisted thoracic surgery through a single port. Proceedings of Thoracic Surgery and Interdisciplinary Symposium on the Threshold of the Third Millennium, Naples, Italy, May 11-13, 2000; pp 29-30. Available online: http://xoomer. virgilio.it/naples2000/index1.html

5. Migliore M, Deodato G. A single-trocar technique for minimally-invasive surgery of the chest. Surg Endosc 2001;15:899-901.

6. Migliore M, Giuliano R, Aziz T, et al. Four-step local anesthesia and sedation for thoracoscopic diagnosis and management of pleural diseases. Chest 2002;121:2032-5.

7. Migliore M. Efficacy and safety of single-trocar technique for minimally invasive surgery of the chest in the treatment of noncomplex pleural disease. J Thorac Cardiovasc Surg 2003;126:1618-23.

8. Nesher N, Galili R, Sharony R, et al. Videothorascopic sympathectomy (VATS) for palmar hyperhidriosis: summary of a clinical trial and surgical results. Harefuah 2000;138:913-6, 1008.

9. Lin TS, Kuo SJ, Chou MC. Uniportal endoscopic thoracic sympathectomy for treatment of palmar and axillary hyperhidrosis: analysis of 2000 cases. Neurosurgery 2002;51:S84-7.

10. Moisiuc FV, Colt HG. Thoracoscopy: origins revisited. Respiration 2007;74:344-55.

11. Sihoe AD. Proper use of history. J Vis Surg 2017;3:185.

12. Singer JJ. The thoracoscope in pulmonary diagnosis. Am Rev Tuberc 1924;10:67-72.

13. Migliore M, Halezeroglu S, Molins L, et al. Uniportal video-assisted thoracic surgery or single-incision videoassisted thoracic surgery for lung resection: clarifying definitions. Future Oncol 2016;12:5-7.

14. Migliore M. Initial History of Uniportal Video-Assisted Thoracoscopic Surgery. Ann Thorac Surg 2016;101:412-3. 
15. Olland A, Reeb J, Sauleau E, et al. Video-assisted thoracoscopic lobectomy versus open thoracotomy conventional lobectomy for stage I non-small cell lung cancer. Cochrane Database Syst Rev 2017. doi: 10.1002/14651858.CD012641.

16. Zhu Y, Liang $M, W u ~ W$, et al. Preliminary results of single-port versus triple-port complete thoracoscopic lobectomy for non-small cell lung cancer. Ann Transl Med 2015;3:92.

17. Zhu Y, Xu G, Zheng B, et al. Single-port video-assisted thoracoscopic surgery lung resection: experiences in Fujian Medical University Union Hospital. J Thorac Dis 2015;7:1241-51.

18. Hirai K, Takeuchi S, Usuda J. Single-port video-assisted thoracic surgery for early lung cancer: initial experience in Japan. J Thorac Dis 2016;8:S344.

19. Fan J, Yao J, Wang Q, et al. Safety and feasibility of uniportal video-assisted thoracoscopic surgery for locally advanced non-small cell lung cancer. J Thorac Dis 2016;8:3543-50.

20. Masmoudi H, Etienne H, Sylvestre R, et al. Three hundred fifty-one patients with pneumothorax undergoing uniportal (single port) video-assisted thoracic surgery. Ann Thorac Surg 2017;104:254-60.

21. Hsiao CH, Chen KC, Chen JS. Modified single-port nonintubated video-assisted thoracoscopic decortication in high-risk parapneumonic empyema patients. Surg Endosc 2017;31:1719-27.

22. Migliore M, Palazzolo M, Pennisi M, et al. Extended uniportal bilateral sympathectomy. J Vis Surg 2018;4:27.

23. Migliore M, Criscione A, Parfrey H. A hybrid singletrocar VATS technique for extracorporeal wedge biopsy of the lingula in patients with diffuse lung disease. Updates Surg 2012;64:223-5.

24. Migliore M, Criscione A, Nardini M, et al. Single incision extended video assisted transcervical thymectomy. J Vis Surg 2017;3:154.

25. Migliore M. Uniportal, single incision VATS for the skeptics. J Vis Surg 2018;4:97.

26. Mineo TC, Ambrogi V. A glance at the history of uniportal video-assisted thoracic surgery. J Vis Surg 2017;3:157.

27. Treasure T. Videothoracoscopic resection for lung cancer: moving towards a "standard of care". J Thorac Dis 2016;8:E772-4.

28. Lerut T. Uniportal video-assisted thoracoscopic surgery in esophageal diseases: an introduction. J Vis Surg 2017;3:182.

29. Augustin F, Schmid T. A word of caution-when uniportal VATS should not be done. J Vis Surg 2018;4:29.

30. Gonzalez-Rivas D. Uniportal thoracoscopic surgery: from medical thoracoscopy to non-intubated uniportal videoassisted major pulmonary resections. Ann Cardiothorac Surg 2016;5:85-91.

31. Nardini M, Bilancia R, Dunning J. Perspective on uniportal thoracic surgery: where do we stand and what is the future. J Vis Surg 2017;3:164.

32. Diethelm PA, Rielle JC, McKee M. The whole truth and nothing but the truth? The research that Philip Morris did not want you to see. Lancet 2005;366:86-92.

33. Diethelm P, McKee M. Denialism: what is it and how should scientists respond?. Eur J Public Health 2009;19:2-4.

34. Keeping scientific advice non-partisan. Lancet 2002;360:1525.
Cite this article as: Migliore M. Uniportal video-assisted thoracic surgery: twentieth anniversary. J Thorac Dis 2018;10(12):6442-6445. doi: 10.21037/jtd.2018.12.49 